\title{
O QUE OS CAVALOS ESTÃO DIZENDO? UMA INTERPRETAÇÃO DA INTERPRETAÇÃO DOS APOSTADORES NAS CORRIDAS DE CAVALOS
}

\author{
Rafael Velasquez ${ }^{1}$
}

Serve de epígrafe uma piada - que escutei durante a realização da pesquisa de campo - para introduzir o leitor diretamente ao tema e ao espírito deste trabalho.

\begin{abstract}
Um sujeito estava apoiado nas grades do padoque olhando os cavalos que estavam circulando antes de entrarem para o canter $^{2}$. Ele olhava para baixo, analisando os cascos dos cavalos, buscando o pé do vencedor. Escutou, de repente, um psiu. Olhou em volta e não viu ninguém. E novamente ouviu: "Ei, psiu!". Procurou com a cabeça e outra vez não viu nada.

"Ei, psiu! Aposta em mim". Ele não acreditou no que parecia ser. Ficou quieto e quando um dos cavalos passou por ele outra vez: "Aposta em mim". Com aquilo o sujeito não pensou duas vezes: correu direto para apostar tudo no cavalo.

No páreo, o cavalo correu, correu, correu e correu... mas nem para a decisão pela fotografia entrou. Ficou de último.

O sujeito ficou, é claro, indignado com aquilo e achou justo ir tirar satisfação pessoalmente com o cavalo. "Escuta aqui, você me disse para apostar em você e você vai lá e... puta merda! PERDE! Que sacanagem é essa?!”.

$\mathrm{O}$ cavalo apenas respondeu:

"Mas além d'eu falar ainda quer que ganhe?".
\end{abstract}

Certa vez cheguei cedo demais na Gávea. As tribunas do hipódromo estavam com pouco movimento. Fui para a arquibancada, para onde costumava acompanhar as corridas ao lado dos rapazes ${ }^{3}$. Tirando o Bigode, que estava abrindo a caixa da pule, não havia mais ninguém. De modo a aproveitar o tempo ocioso, enquanto os rapazes não chegavam, fiquei estudando o programa de corrida numa tentativa de interpretar aquilo que os turfistas ${ }^{4}$ interpretam. E foi assim que Eduardo me encontrou nas arquibancadas: lendo e riscando o programa de corrida.

\footnotetext{
- Aê garoto, tá aí estudando, hein? Estou vendo que hoje as pules irão despencar, hein!

- É. Tô aqui tentando adivinhar quem vai ganhar.

- Ih! Falando em adivinhar, deixa eu te contar a história de um sujeito.
}

\footnotetext{
${ }^{1}$ Universidade Federal Fluminense, Brasil.

${ }^{2}$ Canter, palavra inglesa, se refere ao meio-galope de curta distância. O canter é realizando minutos antes do páreo para que o público possa avaliar o estado físico e o galope do cavalo.

${ }^{3}$ A expressão é mais do que um eufemismo, uma vez que esses "rapazes" estão quase todos na terceira idade. Optei por usar "rapazes" para delimitar um grupo bastante fluido e aberto de pessoas que se encontram num determinado ponto das arquibancadas.

${ }^{4}$ A palavra turfista deriva da palavra turfe, em inglês turf (gramado), que serve para nomear a atividade das corridas. Turfista é empregado para se referir as pessoas que gostam de corrida de cavalo, tanto os que dela participam como os que nela apostam.
} 
Interrompi minha tentativa hermética de leitura dos números presentes no programa para prestar atenção na história que ele ia contar. Na realidade era uma piada - a maioria dos frequentadores, quando não contam piadas, adoram ouvi-las.

A piada era sobre um adivinho. Ele, só de olhar para uma pessoa, era capaz de adivinhar qualquer informação a respeito dela: o número do CPF, o endereço, as cores das roupas íntimas, entre outras coisas. Então, um sujeito admirado com tal capacidade desse adivinho pede para ser seu discípulo. O adivinho fala que possui um curso para adivinhos e que se quisesse poderia ensiná-lo naquele mesmo dia. E assim o sujeito, interessado em aprender, aceita. Segue para a casa do tal adivinho. Ao chegar a casa, o adivinho pede para que ele entre no quarto. Então, o clímax da piada:

- Tire a roupa, disse o adivinho.

O sujeito achou aquilo estranho, mas não desobedeceu.

- Agora fique de quatro em cima da cama.

Como o sujeito desejava aprender aceitou sem questionar. Quando olhou para trás viu o adivinho passando vaselina nas partes.

- Você vai me comer?

- Aí! Já tá começando a adivinhar!

Que diabos esta historieta tem a ver com corrida de cavalo, você pergunta. Eu respondo: tudo. Depois que os outros rapazes chegaram à arquibancada, Eduardo repetiu a mesma piada algumas vezes mais. A expressão "fazer o curso de adivinho" se tornou presente nesse dia, sobretudo nos momentos em que qualquer um de nós parecia querer adivinhar o vencedor da prova de maneira aleatória. A piada, portanto, deixava claro que apostar em corrida de cavalo não se tratava de adivinhação (ou que, pelo menos, não pode ser encarada como tal).

Justamente por não se tratar de adivinhação é que as apostas hípicas não são compreendidas como "jogo de azar". Para os turfistas não faz sentido dizer tal coisa. “Como pode isso ser um jogo de azar se sempre alguém ganha?", me questionou Pita certa vez quando empreguei “jogo de azar” na minha fala. O argumento em defesa é único: acertar nos cavalos não depende da sorte, mas da habilidade.

A diferença entre apostar nos cavalos e apostar em outros jogos de aposta, tais como a roleta, o jogo do bicho ou a loteria federal, está nas probabilidades. Na roleta a probabilidade de a bola cair em uma das 36 casas é de 1 para 35; no jogo do bicho acertar um dos vinte e cinco animais é de 4\% contra 96\%. Nas carreiras hípicas é diferente porque cada cavalo possui características particulares, ou seja, as probabilidades de um determinado cavalo vencer poderão ser de $90 \%$ a $100 \%$ frente a 
determinados cavalos, mas frente a outros, suas probabilidades podem se reduzir para $40 \%$ a $60 \%$. Quero dizer, a chance que cada cavalo tem de vencer é completamente relacional e circunstancial, basta "ler e compreender" o programa de corrida para enxergar isso.

Assim, um turfista, diferentemente de um novato nas corridas, um aventureiro ou um curioso, não escolherá um cavalo ao acaso. É de se esperar de alguém que vá pela primeira vez, que aposte num cavalo porque achou graça do nome ou por considerá-lo bonito, mas não para um turfista experiente. Suas razões para escolher determinado animal, sobretudo quando verbalizadas, precisam se mostrar lógicas e racionais sem quaisquer traços de simpatias numerológicas, superstições astrais ou qualquer outra explicação de ordem mística. Se acaso estes elementos aparecerem no discurso que justifica a escolha, ele corre o risco de cair em descrédito e ter a reputação questionada. "Mas o que isso tem a ver com corrida de cavalo?".

Neste artigo, circunscrevo-me aos processos de estudos do programa de corrida e das análises semiótica e hermenêutica dos cavalos de corrida realizados pelos turfistas-apostadores, a que dei o nome de hipologia. A hipologia é um conjunto de expertises e conhecimentos hípicos acumulados, sempre atualizados, que são mobilizados para a efetivação das apostas. Estes conhecimentos formam uma espécie de "ciência" - com aspas - porém uma ciência inexata (Velasquez, 2015). Quero dizer com isso que apesar de todo o conhecimento é, ainda assim, uma incógnita, pois seria mais uma ciência em construção (Latour, 2000) perpétua.

Inicio este trabalho falando sobre a "construção" do cavalo de corrida, onde se verá como esta "ciência" inexata marca a prática desde o seu nascimento. A partir daí, descreverei como os catedráticos em corridas de cavalos realizam seus estudos para as apostas, divididos em duas partes. Na primeira parte, o estudo hermenêutico do cavalo "no papel" e, na segunda, o estudo semiótico, vendo o cavalo "ao vivo", onde se procura saber o que os cavalos estão dizendo no galope de apresentação, o canter, minutos antes da corrida. Com isso, procuro me situar entre as discussões tanto dos processos de conhecimento como das relações humano-animal sobre as possibilidades de comunicação. 


\title{
O cavalo construído
}

Os cavalos de hipismo em alta velocidade são da raça Puro-Sangue Inglês ${ }^{5}$. O Puro-Sangue surge no final do século XVII e início do XVIII, na Europa, com a mistura de sangues de garanhões árabes e berberes importados e furtados (Barcellos, 2002; Cassidy, 2003). Godolphin, Bierly e Darley são os nomes dos três garanhões que deram origem à raça. Eles, sugere Thomas (2010: 82), "representam uma espécie de Adão, Noé ou Guilherme, o Conquistador, equinos", o que não é pouco.

Mas nesta história da gênese da raça, como bem observou Cassidy (2002), há uma omissão das éguas.

\begin{abstract}
"As éguas que serviram como catalisadoras, de forma que a raça pudesse ser estabelecida, são raramente mencionadas. Pois apenas os antepassados masculinos ${ }^{6}$ desta espécie são visíveis, o sangue original é de gênero e, portanto, diluído quando combinado com o sangue feminino no intuito de gerar um potro" (Cassidy, 2002: $163)$.
\end{abstract}

Sugere, com isso, um reflexo da própria sociedade humana sobre estes animais. Apesar das omissões na história, todos os cavalos (tanto os machos quanto as fêmeas) nascidos e mortos eram - e ainda são - registrados no Studbook, um registro que serve como uma espécie de carteira de identidade desses animais. Na Inglaterra, o Studbook surge em meados do século XVIII. No Brasil, aparece em 1870, na cidade do Rio de Janeiro, mas o primeiro registro de caráter nacional data de 1891, sob a égide do Ministério da Agricultura (Carvalho, 1998: 39).

Tais registros não apenas oferecem um mapa completo da genealogia de cada animal, como atestam sobre a qualidade da linhagem de cada equino. Por isso, ele serve como um norte para os criadores no aperfeiçoamento da raça Puro-Sangue, buscando produzir animais mais habilidosos e velozes a partir das qualidades dos ancestrais; buscando combinar as linhagens.

\footnotetext{
${ }^{5}$ Thoroughbred, em inglês. Há ainda duas raças para corridas, o Puro-Sangue Árabe (Arabian horse) e o Quarto-de-Milha (Quarter horse). No entanto para o turfe é válido apenas o Puro-Sangue Inglês. A única vez que presenciei uma corrida de Puro-Sangue Árabe num hipódromo não houve aposta alguma, foi apenas uma corrida de apresentação para o público com prêmio apenas aos proprietários dos cavalos.

${ }^{6}$ Os nomes dos ilustres cavalos que fazem parte do pedigree são de corredores vencedores de destaque. No entanto, duas figuras masculinas são elementares no pedigree: pai e avô materno.
} 
O pedigree é a essência da criação. Ouvi de alguns proprietários e interessados em reprodução de cavalos que a genética não é tão precisa como se poderia imaginar. Há inumeras nuances que tornam impossível prever o resultado do acasalamento entre os cavalos. Como explica Barcellos:

Por não se tratar de uma ciência exata, criar bons cavalos de corrida sempre dependeu muito mais da capacidade de observação e mesmo da intuição das pessoas, do que de regras padronizadas de conduta. Parece evidente que afluência econômica, para garantir as melhores terras e acesso às boas matrizes e linhagens, conta muito; entretanto, é a capacidade de combinar de modo efetivo todas essas variáveis que faz a diferença entre fracasso e sucesso no desempenho do ofício (Barcellos, 2002: 16).

As variáveis dizem respeito às especialidades ${ }^{7}$ que os ancestrais deixam no fundo genético. Muito embora os espetáculos das corridas equinas tenham o sentido de entretenimento e de aposta para os espectadores comuns,

"para muitos indivíduos da indústria [equestre], o propósito do espetáculo das corridas é testar a raça do Puro-Sangue. O teste do hipódromo meramente estabelece os méritos relativos de cada membro de cada geração e, assim, permite que decisões sejam feitas em relação a sua criação seletiva" (Cassidy, 2002: 157).

As corridas servem para separar o joio do trigo, pois como dizem alguns proprietários e pessoas do meio da compra e venda de cavalos: "cruzar ruim com ruim não vai dar coisa boa, mas se cruzar bom com bom pode ser que dê coisas boas, o que também não é certo".

Apesar de toda seleção criteriosa, de maneira a obter um produto de qualidade, $o$ resultado do cruzamento ${ }^{8}$ pode não ser o esperado. É possível que aparecçam problemas físicos e genéticos, que podem passar despercebidos pelo exame veterinário. Além, ainda, de acontecerem "equívocos" nas escolhas para o cruzamento. Porém, esses "erros" podem fugir a própria regra, o que não é comum, pelo contrário; e quando acontecem surpreendem. E como diz um experiente e apaixonado turfista:

\footnotetext{
${ }^{7}$ As especialidades são a velocidade e a distância. Alguns afirmam que também tem influência sobre o tipo de pista (areia e grama).

${ }^{8}$ As cruzas do PSI acontecem in natura sendo vetada qualquer reprodução in vitro e a clonagem.

${ }^{9}$ No caso, de cruzamentos em que patriarcas aparecem mais de uma vez no pedigree. E pior é quando aparecem muito próximos. Isso não é desejável, sobretudo por conta da semelhança com o incesto.
} 
A experiência já provou que o errado pode dar certo e vice-versa. É a "incerteza gloriosa" que sustenta o turfe; ela conserva a chama da esperança, sem a qual não haveria o turfe, trabalho, amor ou vida. A sabedoria, o autoconhecimento e a cultura ajudam, mas mesmo os sábios e os cultos não sabem o que lhes reserva a jornada. É bom que assim seja (Abujamra, 2011: 149).

Tomo de empréstimo a ideia de "caixa-preta" da cibernética - que são usadas para máquinas ou um conjunto de comandos que se mostram complexos, onde se coloca apenas uma caixa preta, "a respeito da qual não é preciso saber nada, senão o que nela entra e o que dela sai” (Latour, 2000: 14) - para pensar os cavalos (Figura 1). Não se pode partir um cavalo ao meio e saber se está em perfeito estado. Até mesmo não se pode saber o que se passa em seu psicológico antes da corrida, se ele se sente confiante ou inseguro, se está se sentindo bem, ou com cólicas. O que se sabe dele é o seu pedigree, a sua conformação física, a performance que apresentou nas pistas, o treinamento que leva e a reputação do jóquei que o conduzirá porque está escrito no programa de corrida. O resultado na pista é o momento em que se saberá se estava certo ou enganado. Antes da corrida ele é apenas incerteza.

\begin{tabular}{|l|l|ll|}
\hline & $\rightarrow$ & & \\
\hline$\bullet$ Pedigree & & & \\
$\bullet$ Conformação física & & & $\bullet$ Vencedor \\
$\bullet$ Peformance & Cavalo & & $\bullet$ Classificado \\
$\bullet$ Treinamento & & & $\bullet$ Vencido \\
$\bullet \quad$ Jóquei & & & \\
\hline
\end{tabular}

Figura 1: O cavalo enquanto caixa-preta

Entender sobre o pedigree é uma entre tantas outras expertises que os aficionados em corridas de cavalos recorrem para estudar os páreos antes de apostar. E não são todos que dominam tal conhecimento. Conheci pouquíssimos que sabiam dizer de cor as filiações de alguns cavalos de três até cinco gerações. No geral, se recorre às estatísticas de filiações da temporada ${ }^{10}$ como um norteador para o estudo da filiação. Estas estatísticas dizem respeito precisamente aos reprodutores e aos avôs maternos que possuem proles de corredores vecedores. Mas isso é só uma pequena ponta do conhecimento hipológico.

\footnotetext{
${ }^{10}$ Cada temporada corresponde a um ano hípico. No hemisfério sul, o ano hípico é de $1^{\circ}$ de julho a 30 de junho. E a cada virada de ano hípico todos os cavalos mudam suas idades, pois conta-se a idade hípica e não a de nascença. E existem várias outras estatísticas de temporada como: dos jóqueis, dos treinadores, dos proprietários e dos criadores. Todas elas também informam e orientam os turfistas.
} 


\section{A cátedra das corridas de cavalo}

O público aficionado pela corrida está sempre se informando e se atualizando sobre ela. Eles empregam o verbo "estudar" para o ato da leitura atenta e minuciosa dos programas e históricos de corrida. Aqueles que são vistos e considerados como os grandes entendidos no assunto são chamados, com toda a dubiedade, de catedráticos. Isso aparece bem na caricata descrição do catedrático que faz o cronista Luís Edmundo, em toda a sua abrangência e ambiguidade. A descrição data do princípio do século XX que mutatis mutandis se adequa ao tempo hodierno.

[...] o catedrático, tipo curioso do hipismo nacional, geralmente empregado público. [...] Esse homem, que se tem por um técnico formidável em assuntos de corridas, quando repousa na repartição (como um ótimo empregado público, deixando crescer a barba), se não está pensando, está lendo tudo o que existe sobre a próxima corrida e o que divulgam as gazetas da cidade. Conhece, por isso, todos os comentários e potins urdidos sobre a próxima corrida. O homem sabe coisas extraordinárias: a saúde do animal que vai correr, a resistência física do seu jóquei, a capacidade moral do seu proprietário, o que é muito importante, o estado em que se encontra a raia, a verdade sobre cotejos que fazem ao lusco-fusco da madrugada e que morrem no segredo das sombras, sombras que não escrevem secção esportivas nos jornais... Além disso, está apto a informar a filiação, o peso ou a coudelaria de qualquer cavalo com matrícula nos prados da cidade, como diz, igualmente, o número de vitórias que ele já obteve, citando o nome dos jóqueis que o montavam e o tempo que levou nas carreiras, o que deram as poules... Um assombro! O catedrático, porém, espécie de oráculo de Delfos, conhecendo tudo, até o nome do cavalo que vai ganhar, quando joga, é aquela fatalidade: - perde sempre! Mas vai ficando cada vez mais catedrático... (Edmundo, 2003: 530)

O conhecimento na corrida de cavalo é continuum, pois sempre há algo para se aprender - e por isto mesmo inexato. Como disse Bukowski, ele também um aficionado pelas carreiras: "a gente está sempre aprendendo, tanto a respeito de corridas de cavalo como de qualquer outra coisa. e quando se pensa que já se sabe tudo, o aprendizado mal começou" (Bukowski, 1976: 113).

$\mathrm{E}$, apesar de se argumentar que existam determinados princípios que regulam a natureza, ainda assim, acertar o resultado pode deixar a desejar. Não pela falta de conhecimento, mas pela inexatidão do resultado desse conhecimento. Como dizia a máxima de um dos rapazes, o Eduardo: “a regra da corrida de cavalo é a exceção". Por isso, era necessário interpretar os sinais, decifrar os códigos e enxergar aquilo que ninguém mais viu, pois a resposta está nos detalhes. O objetivo, portanto, é encontrar um motivo (ou vários) para apostar em um cavalo e não em outros (ou, então, combinar com outros). 
A primeira parte deste processo começa pela leitura do programa de corrida e, se possível, com o exame do retrospecto ${ }^{11}$. Este é um momento exclusivamente no papel, ou na folha, onde só analisam as informações que estão escritas, sem que se tenha necessariamente a presença do cavalo.

Como é impossível reproduzir toda linha de informações contidas num programa irei por partes, e tomando de modelo apenas um único páreo. Tomo de exemplo o $8^{\circ}$ páreo da $357^{\mathrm{a}}$ renião de domingo de 25 de maio de 2014.

\begin{tabular}{|c|c|c|c|c|c|c|c|c|c|c|c|c|}
\hline \multicolumn{3}{|c|}{ Exata/Dupla/Trifeta } & \multirow{4}{*}{$\begin{array}{c}1100 \mathrm{v} \\
\text { Jóquei ou } \\
\text { aprendiz }\end{array}$} & \multicolumn{9}{|c|}{$\begin{array}{l}\text { Recorde: } 1 \mathrm{~m} 03 \mathrm{~s} 10 \text { - Dollar Fighter }(09.04 .1996) \\
\text { Bolsa: R\$ } 17.278,80 \text {, sendo } 7.700,00 \text { ao proprietário } \\
\text { vencedor; } \mathrm{R} \$ 2.310,00 \text { ao } 2^{\mathrm{o}} \text {; } \mathrm{R} \$ 1.540,00 \text { ao } 3^{\circ} \text {; R } \$ \\
770,00 \text { ao } 4^{\circ} \text { e } \mathrm{R} \$ 385,00 \text { ao } 5^{\circ} \text { colocado. Criadores e } \\
\text { profissionais de acordo com o C.N.C } \\
\text { Produtos de } 3 \text { anos sem vitória no Rio e em São Paulo. } \\
\text { Peso tabela (I) }\end{array}$} \\
\hline \multirow{3}{*}{\multicolumn{2}{|c|}{ Número e Produto }} & \multirow{3}{*}{ Peso } & & \multirow{3}{*}{ Peso } & \multirow{3}{*}{ 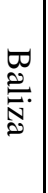 } & \multirow{3}{*}{ Treinador } & \multicolumn{6}{|c|}{ Campanha Total } \\
\hline & & & & & & & \multicolumn{3}{|c|}{$\begin{array}{l}\text { Areia e } \\
\text { Grama }\end{array}$} & \multicolumn{3}{|c|}{ Só Grama } \\
\hline & & & & & & & $\mathrm{S}$ & $\mathrm{V}$ & $\mathrm{C}$ & $\mathrm{S}$ & $\mathrm{V}$ & $\mathrm{C}$ \\
\hline \multicolumn{2}{|r|}{ 1) Girador } & Est. & $\begin{array}{l}\mathrm{M} \\
\text { Almeida }\end{array}$ & 57 & 1 & LJ Reis & 05 & 01 & 04 & 01 & 00 & 01 \\
\hline 2 & Bravo Gianni & 491 & $\begin{array}{l}\text { B } \\
\text { Pinheiro } \\
3 \\
\end{array}$ & $57 / 4$ & 2 & J Jaime & 13 & 00 & 10 & 05 & 00 & 04 \\
\hline 3 & Empire Fair (L) & 466 & $\begin{array}{l}\text { A Maciel } \\
2\end{array}$ & $57 / 5$ & 3 & B Piovesan & 05 & 00 & 02 & 03 & 00 & 00 \\
\hline 4 & Journaliste (L1) & 424 & $\begin{array}{l}\text { AF } \\
\text { Matos }\end{array}$ & 57 & 4 & LJ Resis & 04 & 00 & 02 & 03 & 00 & 02 \\
\hline 5 & Dom de Correr & 468 & D Duarte & 57 & 5 & $\begin{array}{l}\mathrm{JC} \\
\text { Coutinho }\end{array}$ & 04 & 00 & 02 & 01 & 00 & 00 \\
\hline \multicolumn{2}{|r|}{6 Heart-Free } & 504 & B Reis & 57 & 6 & $\begin{array}{l}\text { VS } \\
\text { Pedersen }\end{array}$ & 02 & 00 & 00 & 02 & 00 & 00 \\
\hline 7 & Bebê Macio (L1) & 485 & $\begin{array}{l}\mathrm{R} \\
\text { Salgado }\end{array}$ & 57 & 7 & M Ferreira & 07 & 00 & 03 & 04 & 00 & 01 \\
\hline 8 & All Straws & 474 & $\begin{array}{l}\text { Jean } \\
\text { Pierre }\end{array}$ & 57 & 8 & SB Vieira & 10 & 03 & 04 & 00 & 00 & 00 \\
\hline \multicolumn{2}{|r|}{\begin{tabular}{l|l}
9 & Inesquecivelzeppe \\
\end{tabular}} & Est. & V Borges & 57 & 9 & O Loezer & 04 & 01 & 03 & 00 & 00 & 00 \\
\hline
\end{tabular}

\footnotetext{
${ }^{11}$ O programa de corrida fica disponível gratuitamente na entrada do hipódromo, bem como no seu interior. O retrospecto está disponível on-line no site do Jockey Club Brasileiro, são poucos que se dispõem a imprimi-lo. A grande maioria do público do hipódromo usa o retrospecto disponível na revista semanal Turfe Brasil (ver a nota de rodapé 17), que é paga, pois traz também algumas indicações.
} 
Nesta primeira parte temos as informações básicas: número do páreo, o horário, distância da prova (1100 metros), pista ("v" de variate ${ }^{12}$, que é na areia), o recorde e a chamada da prova: "produtos de 3 anos sem vitória...".

Em seguida estão os números e os nomes dos cavalos ${ }^{13}$, o peso de quando correram pela última vez ${ }^{14}$ o nome do jóquei ou do aprendiz de jóquei que montará e o peso que irá carregar, o nome do treinador. O peso do cavalo no dia da prova é anunciado pelo locutor e aparece nos televisores, informando se está com quantos quilos a mais ou a menos do que está no programa. Muitos tomam nota dessa informação (esse é um detalhe, como todos os outros, importante).

A campanha total é uma síntese númerica de quantas vezes os cavalos saíram (s), venceram (v) e se classificaram (c). É repetido duas vezes, uma com as duas pistas, outra exclusiva para grama, o negrito e itálico serve para distinguir (esse padrão se repetirá na segunda parte).

Antes de apresentar a segunda parte é preciso dizer que estas informações são pontos iniciais para os cálculos do estudo hípico, que são: campanha + a capacidade física e moral do jóquei + peso + a reputação de treinador. As informações sobre a moral do jóquei e a reputação do treinador acontecem tanto por suas respectivas estatísticas como pelas histórias e os boatos que circulam pelo hipódromo (que são informações que não aparecem no jornal e nem na revista do turfe ${ }^{15}$ ).

\begin{tabular}{|c|c|c|c|c|c|c|c|c|c|}
\hline \multicolumn{4}{|c|}{3 Colocações, Data e Última Apresentação } & \multirow{2}{*}{$\begin{array}{c}\begin{array}{c}\text { Dist/ } \\
\text { Pista }\end{array} \\
1.2 \mathrm{nl} \\
\end{array}$} & \multirow{2}{*}{$\begin{array}{c}\text { Tempo } \\
75 \mathrm{~s} 4 \\
\end{array}$} & \multirow{2}{*}{$\begin{array}{c}\text { Rateio } \\
6,0 \\
\end{array}$} & \multicolumn{3}{|c|}{$\begin{array}{c}\text { Sexo/Pelo Idade } \\
\text { Origem }\end{array}$} \\
\hline \begin{tabular}{l|l|}
3 & 2 \\
\end{tabular} & 3 & 11.04 & 1.(07) Euro Gais $41 \frac{1}{4} \mathrm{pr}$ & & & & MT & 3 & PR \\
\hline \begin{tabular}{l|l|}
2 & 2 \\
\end{tabular} & 7 & 28.02 & 4.(06) Vai Levando 10 3/4 & $1.2 \mathrm{am}$ & $79 \mathrm{~s} 2$ & 3,2 & $\mathrm{MC}$ & 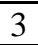 & SP \\
\hline \begin{tabular}{l|l|}
4 & 4 \\
\end{tabular} & 3 & 20.04 & 8.(10) Basil $81 \frac{1}{2}$ & $1.0 \mathrm{gm}$ & $58 \mathrm{~s} 0$ & 37,4 & $\mathrm{MC}$ & 3 & PR \\
\hline \begin{tabular}{l|l|}
3 & 3 \\
\end{tabular} & $\overline{7}$ & 13.01 & 7.(08) Bordello 24 1⁄2 cj & $1.2 \mathrm{np}$ & $71 \mathrm{~s} 2$ & 12,3 & $\mathrm{MC}$ & 3 & $\mathrm{RS}$ \\
\hline \begin{tabular}{|l|l|}
5 & 6 \\
\end{tabular} & 6 & 10.03 & 4.(07) Morena Marina 5 1/4 & $1,1 \mathrm{np}$ & $70 \mathrm{~s} 5$ & 3,6 & $\mathrm{MC}$ & 3 & $\mathrm{PR}$ \\
\hline \begin{tabular}{l|l|}
0 & 0 \\
\end{tabular} & $\boldsymbol{U}$ & 03.05 & $\begin{array}{l}\text { 7.(09) Olympic Dusseldorf } 6 \\
1 / 4\end{array}$ & $1.0 \mathrm{gm}$ & $57 \mathrm{~s} 5$ & 6,0 & $\mathrm{MC}$ & 3 & RS \\
\hline \begin{tabular}{l|l|}
$x$ & $\mathrm{u}$ \\
\end{tabular} & 3 & 24.02 & $\boldsymbol{u} .(13)$ Jorge Baú $21^{1 / 4}$ & $1.5 \mathrm{gl}$ & $90 \mathrm{~s} 3$ & 27,0 & $\mathrm{MC}$ & 3 & RS \\
\hline \begin{tabular}{l|l|}
7 & 4 \\
\end{tabular} & $\mathrm{u}$ & 05.05 & 7.(09) Baigorra 18 3/4 & $1.3 \mathrm{~nm}$ & $81 \mathrm{~s} 8$ & 2,9 & $\mathrm{MC}$ & 3 & RS \\
\hline $\begin{array}{ll}\mathbf{4} & 3 \\
\end{array}$ & 1 & 21.03 & $\begin{array}{l}\text { U.(06)Viyageur de Paris } 10 \\
3 / 4 \mathrm{pr}\end{array}$ & $1.1 \mathrm{ne}$ & $68 \mathrm{~s} 0$ & 8,0 & $\mathrm{MC}$ & 3 & $\mathrm{SC}$ \\
\hline
\end{tabular}

\footnotetext{
${ }^{12}$ Ver nota 19.

${ }^{13}$ É costume o número do cavalo corresponder ao número da baliza em que irá largar. O primeiro número é o de dentro da pista. O (L) e (L1) logo após o nome do cavalo indica que o cavalo foi medicado com Lasix (Fusosemida), sendo L1 para primeira vez de uso.

${ }^{14}$ Se não correu antes aparecerá “est." - abreviação para estreante.

${ }^{15} \mathrm{Na}$ revista saem às resoluções da Comissão de Corrida em que aparecem as suspensões e multas de jóquei e treinadores, conforme as regras. Mas tais resoluções não são notícias e nem boatos, apenas as alimentam.
} 
Nesta segunda parte consta novamente o numeral, a campanha das três penúltimas apresentações; é, como se lê, da esquerda para a direita. Seguindo o padrão de negrito e itálico para grama. $O$ " $x$ " representa colocação acima do $9^{\circ}$ lugar, o "u" é de último. Em seguida vem a data da sua última corrida, a colocação, entre parênteses o número de cavalos no páreo, o nome do vencedor (no caso de vitória, o nome do segundo lugar), após o nome é a distâcia em corpos (de cavalo) do primeiro colocado.

A distância e a pista aparecem abreviados. 1.0 é abreviação para 1.000 metros, por exemplo. Quanto à pista, a primeira letra é para espeficicar o tipo: "a" para areia, "g" para grama e "n" para noite (sendo noite fica sem saber se é areia ou grama - a não ser pelo detaque em negrito); a segunda diz respeito a condição física da pista: "l” para leve, "m" macia, "p" pesada e "e" encharcada. Depois vem o tempo da prova, medido pelo primeiro lugar. Em seguida o rateio que esse cavalo fechou no dia da corrida.

O sexo vem representando de forma clara, M para macho (fêmeas serão $\mathrm{F}$, os animais castrados aparecem com $\mathrm{C}$ ), ao lado a pelagem: $\mathrm{T}$ de tordilho ${ }^{16}, \mathrm{C}$ de castanho e A de alazão ${ }^{17}$. A idade hípica do cavalo e a sigla do Estado de nascimento.

Tirando o sexo, pelagem e estado de nascimento, nessa segunda parte é igualmente importante para a análise saber com quem correu, a velocidade e o seu rateio. Esses elementos são indícios que entram no cálculo que apresentei acima.

\begin{tabular}{|c|c|c|c|c|}
\hline B & Cor da Blusa & Filiação & Criador & Proprietário \\
\hline 1 & $\begin{array}{l}\text { Br, símbolo lar/br/az-mar/boné } \\
\text { lar/az lts.vts }\end{array}$ & $\begin{array}{l}\text { Bonapartiste / } \\
\text { Ellefrance }\end{array}$ & Eloi José Quege & Stud Allstar Brasil \\
\hline 2 & $\begin{array}{l}\text { Az-mar.,mgs.rosa/az-mar. Em } \\
\text { xdz,boné rosa }\end{array}$ & $\begin{array}{l}\text { Choctaw Rigde / } \\
\text { Procuradora }\end{array}$ & $\begin{array}{l}\text { Hermano Antonio } \\
\text { Henning }\end{array}$ & $\begin{array}{l}\text { Fernando Antonio } \\
\text { F. Monteiro }\end{array}$ \\
\hline 3 & Ouro e azul em metade vertical & $\begin{array}{l}\text { Redattore / Noble } \\
\text { Dear }\end{array}$ & Haras Springfield & $\begin{array}{l}\text { Eduardo Carvalho } \\
\text { Lubianca }\end{array}$ \\
\hline 4 & Ouro,gregas,mangas e boné azul & $\begin{array}{l}\text { Arambaré/Legendo } \\
\text { of Tijucas }\end{array}$ & Haras Malunga & Stud Marisa Star \\
\hline 5 & $\begin{array}{l}\mathrm{Br} \text {, pala verde esc/bege esc, mgs } \\
\mathrm{Br} / \mathrm{vd} / \text { bege }\end{array}$ & $\begin{array}{l}\text { Quais/Irmã } \\
\text { Angélica }\end{array}$ & $\begin{array}{l}\text { Haras } \\
\text { Girassóis }\end{array}$ & Haras The Best \\
\hline 6 & $\begin{array}{l}\text { Az-mar,estrelas,mangas e boné } \\
\text { azul-celeste }\end{array}$ & $\begin{array}{l}\text { Elusive } \\
\text { Quality/Innocent } \\
\text { Lady }\end{array}$ & $\begin{array}{l}\text { Haras } \\
\text { internacional }\end{array}$ & Stud \\
\hline 7 & $\begin{array}{l}\text { Grená, cruz de santo andré e } \\
\text { boné ouro }\end{array}$ & Good Reward/Dica & $\begin{array}{l}\text { Stud Eternamente } \\
\text { Rio }\end{array}$ & Stud Ilse \\
\hline 8 & $\begin{array}{l}\text { Ouro,cruz de santo andré e boné } \\
\text { verd }\end{array}$ & $\begin{array}{l}\text { True } \\
\text { Confidence/Straw } \\
\text { Baby }\end{array}$ & $\begin{array}{l}\text { Ismar Fagundes } \\
\text { de Azambuja }\end{array}$ & $\begin{array}{l}\text { José Luiz de } \\
\text { Azevedo Marinho }\end{array}$ \\
\hline 9 & $\begin{array}{l}\text { Azul,cruz sto.andré verde e } \\
\text { cinza,boné azul }\end{array}$ & $\begin{array}{l}\text { Tiger } \\
\text { Heart/Alfattah }\end{array}$ & Haras Tessarollo & $\begin{array}{l}\text { Coudelaria } \\
\text { Mussi }\end{array}$ \\
\hline
\end{tabular}

${ }^{16}$ Tordilho é um cavalo branco com pequenas manchas pretas. Nota da Revisão Técnica.

${ }^{17}$ Alazão é um cavalo de cor marrom, tendendo ao avermelhado. Nota da Revisão Técnica. 
Na terceira e última parte, temos a descrição abreviada da forma e das cores das fardas dos próprietários. Depois a filiação dos cavalos, em ordem, pai/mãe ${ }^{18}$. O nome da pessoa física ou jurídica (stud, coudelaria ou haras) do criador do cavalo. E o nome da pessoa física ou jurídica do proprietário do cavalo.

De maneira a não tomar demasiado espaço, apresentarei o retrospecto, tal como é disponibilizado no site e na revista ${ }^{19}$, tomando como exemplo um único cavalo. Farei do Empire Fair que foi o vencedor do páreo tomado de exemplo.

\begin{tabular}{|c|c|c|c|c|c|c|c|c|c|c|c|c|c|}
\hline \multirow{2}{*}{\multicolumn{2}{|c|}{\begin{tabular}{|l} 
3- EMPIRE FAIR \\
A Maciel (Ap 2 $)$ \\
\end{tabular}}} & \multicolumn{5}{|c|}{ Redattore e Nobre Dear (Ghadeer) } & \multicolumn{5}{|c|}{ Haras Springfield } & \multicolumn{2}{|c|}{ MC 17/10/10-PR } \\
\hline & & & & & $\bar{B} \mathbf{F}$ & ovesan & & & & $\overline{\operatorname{tar}}$ & $\overline{\mathbf{O C}}$ & arvalho Lubian & \\
\hline $\begin{array}{l}20 / 04 / \\
14\end{array}$ & $8^{\circ}(11) 08$ & F Chaves (L) & 54 & A & 466 & 1,0 GM- & $56 " 08$ & 37,4 & $\mathrm{NO}$ & $3^{\circ}$ & & sil, Balzaquiana & $81 / 2$ \\
\hline $\begin{array}{l}07 / 04 / \\
14\end{array}$ & $3^{\circ}(08) 10$ & F Chaves (L) & 57 & A & 466 & $1,1 \mathrm{AMV}$ & 1'09'91 & 14,6 & $\mathrm{NO}$ & $5^{\circ}$ & & gned Fly, Boss & $43 / 4$ \\
\hline \begin{tabular}{|l|}
$21 / 03 /$ \\
14
\end{tabular} & $4^{\circ}(08) 02$ & A Correia $(\mathrm{L})$ & 57 & A & 464 & $1,2 \mathrm{AMV}$ & $1 ' 15$ '76 & 33,5 & $\mathrm{NO}$ & $3^{\circ}$ & & pster, Botany & $1 / 4$ \\
\hline \begin{tabular}{|l|}
$21 / 09 /$ \\
13
\end{tabular} & $3^{10^{\circ}(10) 0}$ & M Ribeiro & 56 & & 464 & $1,4 \mathrm{GM}$ & 1 '24"28 & 32,5 & $\mathrm{NO}$ & & & $\begin{array}{l}\text { Walker, Joy } \\
\text { alker }\end{array}$ & \begin{tabular}{|l|}
11 \\
$1 / 2$ \\
\end{tabular} \\
\hline $\begin{array}{l}10 / 08 / \\
13 \\
\end{array}$ & $8^{\circ}(10) 03$ & V Sousa & 56 & & 470 & $1,0 \mathrm{GL}$ & $54 " 80$ & 32,0 & NO & & & spio, Carbonero & \begin{tabular}{|l|}
14 \\
$1 / 4$ \\
\end{tabular} \\
\hline
\end{tabular}

O retrospecto de um único cavalo, como se vê, é complexo. Imagine-se todos os cavalos do páreo numa folha, um atrás do outro. O interessado em estudá-lo precisa se familiarizar com a ordem, com os números e com as siglas presentes nele para ter ciência do que está lendo.

Em linha: número e nome do cavalo, o nome do pai, da mãe e do avô materno entre parênteses, nome do criador, sexo, pelagem, data de nascimento e estado; o nome do jóquei que irá montá-lo, o peso que o jóquei levará, nome do treinador, nome do proprietário.

O retrospecto é efetuado da corrida recente para a mais antiga. Lê-se: a data da sua apresentação, a classificação, o número de participantes entre parênteses, o número da baliza que saiu, o nome do jóquei (o "L" ao lado do nome é que estava sob

\footnotetext{
${ }^{18}$ Por pedido dos turfistas foi colocado, posteriormente, após o nome da mãe, entre parênteses, o nome do avô materno. Tal mudança acabou gerando um novo reordenamento das informações do programa de corrida. Quando estava no fim do trabalho de campo essa nova organização do programa estava em teste.

${ }^{19}$ Revista Turfe Brasil é uma revista semanal que traz algumas notícias e crônicas do turfe brasileiro e também algumas notas do turfe internacional. Seu conteúdo predominante são os retrospectos de todos os cavalos de todas as corridas nacionais que acontecem nos quatro grandes hipódromos brasileiros: Paraná, Rio Grande do Sul, São Paulo e Rio de Janeiro.
} 
medicação de Lasix), o peso do jóquei, o ferrageamento ${ }^{20}$, o peso do cavalo, a distância da prova, a condição da pista, a distância da cerca móvel ${ }^{21}$, o tempo do páreo, o rateio, a categoria do páreo, a colocação na entrada da reta final, os primeiros colocados, a diferença em corpos em relação ao primeiro colocado.

O retrospecto pode ser tirado no website do Jockey Club ou comprando a revista semanal. A revista é mais popular entres os turfistas, sendo uma espécie de "bíblia do turfe" - como qualificou um deles, pois além dos retrospecto traz todas as estatísticas da temporada. As informações contidas nestes retrospectos são cruzadas e somadas ao belprazer do catedrático, procurando sempre os "detalhes" que possam fazer a diferença na interpretação do estudo hípico.

Alguns exemplos desses cruzamentos de dados são os seguintes: se o cavalo é pilotado sempre pelo mesmo jóquei; se teve vitórias com um mesmo jóquei ou se foi com outro, pode ser que não se repita a façanha (pelo jóquei não conhecer o cavalo e, também o inverso, o cavalo não conhecer o jóquei). Observam-se as colocações e os pesos: se o cavalo se classifica melhor quando está com mais ou menos peso, e, assim, compara-se com o peso atual. A classificação na corrida e a classificação na entrada da reta indicam a velocidade que o cavalo teve nos metros finais, evidenciando sua velocidade. A distância que correu antes e que correrá agora. A pista e a sua qualidade quando teve suas vitórias pode indicar uma preferência de pista pelo cavalo. Outro detalhe que não pode passar despercebido é a classificação dos páreos que o cavalo correu: se correu em provas especiais ou de grupo, atesta-se uma qualidade ao correrdor; se só corre páreos comuns atenta-se outra qualidade, e se correu em páreos de claiming $^{22}$ ainda uma outra. Além de muitos outros cruzamentos possíveis.

Como disse, todas estas informações são lidas e estudadas previamente, sem que se necessite ter os cavalos diante de si. Os turfistas geralmente estudam o programa de véspera e levam, no dia da corrida, anotações pessoais do que acreditam ser(em) o(s) melhor(es) cavalo(s) de cada páreo. Geralmente, tais notas servem para fazer as apostas

\footnotetext{
${ }^{20}$ Ferrageamento nada mais é do que o uso da ferradura no cavalo. A letra "A" indica ferradura de alumínio. Quando o cavalo corre desferrado, isto é, sem o uso da ferradura, se indica com a letra " $D$ ". Nas duas últimas apresentações Empire Fair correu em São Paulo, provavelmente por isso não se registrou o uso de ferradura e a sua colocação na entrada de reta (adiante).

${ }^{21} \mathrm{O}$ uso da cerca móvel é só na pista de grama. Ela serve para conservar a grama do lado de dentro da pista. A distância da cerca móvel altera alguns metros na distância da prova (mais um detalhe). Na pista de areia o que tem de diferente é a curva da variante que é representada com "V".

${ }^{22}$ Páreos de claiming são provas em que todos os cavalos inscritos são passíveis de serem comprados com valores de remate, conforme regulamento próprio.
} 
em modalidades como mais de um cavalo, e as acumuladas ${ }^{23}$ onde precisam indicar os vencedores de mais de um páreo antes de darem início às corridas.

Quando se aposta em páreo após páreo, mais do que olhar o papel é necessário ver e enxergar o cavalo. Há aqueles que preferem exclusivamente apostar assim, depois de verem os cavalos, como uma espécie de "ver para crer". E são três os momentos possíveis que se pode observar os cavalos.

Parto do mais raro ao mais comum. O turfista com tempo, e enturmado com alguns treinadores, poderá visitá-los nas cocheiras ${ }^{24}$ e ver como estão os cavalos sob os cuidados desses respectivos treinadores (e se limitará a ver apenas os cavalos desses treinadores conhecidos e não dos outros). E, mais do que simplesmente ver os cavalos, receberá, provavelmente, algumas informações dos treinadores a respeito dos equinos e o que esse treinador sabe a respeito dos cavalos dos outros treinadores. De qualquer forma, há muito mais a avalição do treinador do que uma análise hipológica do cavalo em si neste caso.

O segundo momento: após os cavalos passarem por alguns procedimentos veterinários $^{25}$, eles vão para o padoque guiados pelos seus respectivos cavalariços e caminham em círculos, aguardando os jóqueis para os conduzirem para entrar na pista. É no momento dessa caminhada que começam as observações apuradas.

Nos “dez mandamentos do apostador", escrito por Phil Bull (em Barcellos, 2002: 77), o autor diz, no seu segundo mandamento, que

É no padoque que $80 \%$ dos vencedores de qualquer páreo "falam" sobre o que vai ocorrer alguns minutos depois. $\mathrm{O}$ apostador tem que entender o que os animais estão "dizendo" enquanto caminham desmontados. Um vencedor provável quase sempre exibe isso no pelo; na quantidade exata de "graxa" que carrega; na atitute correta diante do público; no comportamento em relação ao cavalariço que o conduz; na tonicidade dos músculos da anca; no ritmo e determinação das passadas. Um pelo opaco, suor em demasia, cabeça baixa, desânimo, claudicação no andar, músculos soterrados por banha, irritabilidade em relação ao cavalariço (principalmente quando começam a dar voltas em torno dele), a recusa de serem conduzidos, são sinais de advertência dos animais, que têm de ser entendidos por aqueles que arriscam seu dinheiro neles.

\footnotetext{
${ }^{23}$ Acumuladas são apostas em que se indicam os páreos e os cavalos em que irão apostar. O apostado é multiplicado pelo rateio do cavalo, que multiplica com o rateio do páreo seguinte até o último, desde que não erre.

${ }^{24}$ Há, dentro das dependências do Hipódromo, vilas de cocheiras onde moram os treinadores e alguns cavalariços.

${ }^{25}$ Esses procedimentos veterinários são para checar se o cavalo que o cavalariço trouxe é o mesmo que está inscrito no programa. Confere-se a carteira de identidade do animal e o chip implantado no seu pescoço. Pesam o cavalo, verificam se está com a ferradura adequada e, finalmente, se o cavalo está apto ou não para correr.
} 
Essa enumeração dos sinais feita por Bull parece-me uma perfeita compilação da semiótica que os turfistas empregam nesse momento. E é através desse olhar que uma comunicação subjetiva se torna possível. Este é o único argumento subjetivo que pode ser expresso sem que se caia em descrédito, como os outros. Porque se compreende que o apostador "entendeu" o cavalo, mas não o contrário. Se é o cavalo que entende o homem, como se diz, é caso psiquiátrico.

O terceiro e último momento é o canter. O canter é o meio-galope que os cavalos fazem montados pelos jóqueis, minutos antes de ser dada a largada. Esse é um momento muito importante para os turfistas. Costuma-se dizer que pode passar uma mulher completamente nua na arquibancada no momento do canter que ninguém a irá notar. De fato, toda conversa se interrompe no momento em que é realizado e só retorna no final.

No terceiro mandamento de Bull: "confirme no canter o que os cavalos já ‘informaram' no padoque”. A explicação que ele fornece são de outros exames precisos da semiótica hipológica:

\begin{abstract}
O canter diferencia os que caminham bem ("good walker"), dos que galopam bem ("good movers"). Um bom canter, desses que atraem o dinheiro do apostador - ou fazem dobrar a quantia jogada - pressupõe um animal equilibrado, disciplinado, "on the bit", orelhas posicionadas para a frente, movendo-se com fluidez (principalmente no momento em que todo o peso dos ombros está sendo suportado apenas por uma das mãos), e que diminui seu ritmo assim que solicitado pelo jóquei. Desconfie dos galopes esfuziantes, dos cavalos incontroláveis, das cabeças tortas pela pressão das rédeas, e desconfie, ainda mais, daqueles que disparam no canter, ou têm que ser incentivados pelo chicote para iniciar o movimento. Neste caso, dependendo da situação, diminua a aposta, ou simplesmente a cancele (Barcellos, Idem: 77-8).
\end{abstract}

O canter é importante por ser o momento em que os cavalos estão dizendo alguma coisa. Mas o que os cavalos estão dizendo? Eles estão "falando" se vão ganhar ou não a corrida. Testemunhei algumas vezes os rapazes dizerem que determinado cavalo "passou no canter pedindo pule ${ }^{26 "}$. Às vezes, sugerem que os animais comunicam no canter já o que é sugerido nos seus nomes, como, por exemplo, Godmustbecrazy, Diesel, Quero Ganar... História e piada com esses e outros nomes é o que não falta no repertório dos apostadores.

\footnotetext{
${ }^{26}$ Pule é o nome que se dá ao ato e ao bilhete da aposta.
} 
E há sempre uma frustração quando o jóquei faz o canter destribado, ou mesmo, quando o cavalo passa "preso", puxado pelas rédeas pelo punga ${ }^{27}$. Quando isso acontece, o público demonstra duas coisas: de que não se quer mostrar aquilo que o cavalo é capaz de fazer como também aquilo que ele não é. A desconfiança é livre, uma vez que a suspeita de "roubo" e de "malandragem" alimentam a rivalidade dentro do hipódromo (Velasquez, 2015). Mas independente desses "travamentos”, o que importa, no fundo, é que o cavalo está dizendo sempre alguma coisa aos humanos. E os cavalos só falam nesse único momento, pois ele não se repete.

Durante a pesquisa de campo houve uma curiosa circunstância relativa ao olhar durante o canter, um olhar naturalístico e interpretativo sobre a natureza. Eu estava sentado, como de costume, com os rapazes do lado externo da tribuna assistindo aos páreos. Devíamos estar no $5^{\circ}$ ou no $6^{\circ}$ páreo do dia. Como o tempo estava virando, um deles comentou que a meteorologia previa chuva para o dia seguinte. Um pouco depois disso, outro apontou para a quantidade de urubus que enchiam o firmamento. Eram inúmeros. Boneca, com seus trejeitos de malandro, ficou olhando aquilo e arriscou:

- Se aquele grupo [de urubus] continuar voando por ali [à sudoeste] não vai chover. Mas, agora, se passarem a voar para lá [à su-sudoeste] vai chover.

Ao dizer isto Boneca estava claramente demonstrando o seu capital naturalístico, de ver e entender o que a natureza informava, para os demais. Mas ninguém pareceu dar grande atenção para a sua previsão do tempo por meio do voo dos urubus. E com o passar das horas, o bando não foi para su-sudoeste, o que apontava que a previsão do Boneca estava indo contra a previsão do tempo oficial.

Longos minutos mais tarde, precisamente no canter do penúltimo páreo do programa, como de costume, todos prestavam atenção aos cavalos que se apresentavam naquele momento. Após o último potro fazer seu galope, Boneca, novamente, aparece com outra observação interpretativa, mas desta vez sobre o cavalo:

- Há muito tempo que não vejo um canter bonito como desse número seis [o Cartouche]. Que categoria de galope! Bonito. Na medida, como tem que ser. É - e voltou a dizer para si mesmo - Há muito tempo que não vejo um troço assim.

\footnotetext{
${ }^{27}$ Pungas são como são chamados os cavalos e os cavaleiros de apoio. Eles servem para capturar algum cavalo que escape e para guiar os animais que estão "nervosos" durante o canter.
} 
Novamente, ninguém pareceu dar atenção para o que Boneca dizia. Tenho duas hipóteses para o aparente desdém. A primeira delas, um tanto que banal, seria o descrédito pela previsão de chuva por meio dos urubus. A segunda, a partir da hipologia, é que se tratava de um páreo para produtos de 3 anos sem vitória. O potro Cartouche tinha uma campanha de seis corridas: 2 segundos lugares, 1 terceiro lugar e 2 quintos lugares. Mas, olhando para a campanha dos adversários era relativamente similar, com pouca discrepância numérica. No entanto, este era um produto de criação e de propriedade do Haras Santa Maria de Araras, que à época figurava como líder da estatística de criador e entre os primeiros de proprietário. Além disso, o animal era filho de Wild Event, um dos líderes da estatística dos reprodutores daquela temporada. O totalizador sinalizava o favoritismo de Cartouche em 2,6 para 1. E, assim, o que Boneca estava falando, a partir do canter, muitos outros também acreditavam, independentemente do que dizia sobre o acontecimento, pois já era favorito antes de entrar na pista. Na verdade, o canter era a confirmação do papel, por isso um dos favoritos no rateio.

Cartouche venceu atropelando os adversários nos 100 metros finais. Ninguém ali sentando conosco pareceu ter acertado além do Boneca e de mim, que fui na sua onda. Mas, para falar a verdade, também ninguém ficou surpreso com a vitória. Alguns deles haviam apostado no potro do Santa Maria, porém não o jogaram como vencedor, mas colocando-o na dupla, na exata, na trifeta. Outros haviam se arriscado em outros cavalos que tinham também bons papéis. Boneca gritava de alegria.

- Você tinha razão em ver no canter... - tentei puxar conversa, mas antes mesmo de poder concluir ele me atropelou, tal como Cartouche atropelou os adversários, com o ardor da vitória.

- Aqui - se referindo aos rapazes, em voz alta - ninguém sabe de nada. Ninguém sabe nada! É tudo neném! Ninguém sabe é nada! Na próxima vez que ver um canter assim não vou apostar só 10 reais, vou apostar 1 milhão! 1 trilhão! E não vou falar nada. Tudo neném!

E bom, no dia seguinte, houve pancadas de chuva.

Aprender a olhar os cavalos enquanto correm, um atrás do outro, e tirar dali conclusões não é fácil. É preciso ter visto muitos cavalos e apreciado bons galopes de excelentes animais e, claro, se lembrar deles. Também é necessário comparar o que se viu no cavalo com o que enxergou no papel, ou o contrário. De qualquer modo, é 
necessário sempre o acúmulo de conhecimento hípico sobre corredores. Portanto, a hipologia é esse processo continuum de canter atrás de canter, de páreo atrás de páreo, reunião após reunião, de estudos em cima de estudos e, certamente, de incansáveis observações que vão tornando o turfista “cada vez mais catedrático...”.

\section{O entender e o aprender: sobre o ser catedrático}

O processo de se tornar catedrático em corrida de cavalo é infindável. O turfista se absorve completamente nas ações de desvendar os significados dos programas e dos sinais produzidos pelos cavalos. Vão, assim, cruzando e multiplicando variáveis matemáticas com a subjetividade da interpretação. Não há nada mais denso e tenso do que escolher o cavalo que irá apostar seu dinheiro.

A tensão marca a incerteza. Pois a tensão é o elemento que confere um valor ético, uma vez que oferece ao apostador as suas qualidades, isto é, suas habilidades, expertises, conhecimento, status, tenacidade, entre outros (Huizinga, 2010). No ato da aposta, o cavalo passa a representar as capacidades daquele que nele aposta. O dinheiro é o que os conecta. Assim, o cavalo e o turfista perdem ou ganham "juntos". A perda ou o ganho do dinheiro se solidifica na vida do jogador, podendo com isso se gabar, como também, ser rebaixado no âmbito do jogo, simbolicamente falando.

O cavalo é um enigma, revela-se uma caixa-preta. É a incerteza que anima as apostas. A hipologia é a conviç̧ão do turfista para desvendar esse enigma. É a certeza na incerteza. E nesse jogo não se pode ficar com muito " $e$ se...", pois uma atitude como essa, penso, não leva alguém a qualquer lugar, não realiza absolutamente coisa alguma, seja nas corridas de cavalo, na antropologia ou mesmo na vida.

Eu havia desabafado com dois "nativos" sobre meu dilema de apostar ou não nas corridas. Um dia vi um cavalo, ele me pareceu ser o exemplo daquilo que estava aprendendo. Tomei nota do seu número e separei o dinheiro que iria apostar. Quando o jóquei montou nele para conduzi-lo à pista o cavalo me olhou, virando a cabeça na direção em que estava. O "ei, psiu" da epígrafe ecoou na minha cabeça. Entrei na fila para comprar a pule: "e se estou sendo afetado?". "E se perder?". "E se isso prejudicar minha pesquisa?". “E se...”. O cavalo ganhou, ao fim, com uma pule razoável. Não apostei nada. Os dois, Pita e Quequé, riram da minha história e do meu dilema. "Esse 'e 
se...' é que é foda!", disse Quequé, "Se ficar nessa você não faz nada, e também nada acontece".

Ele estava certo. Agindo assim, sem apostar, você poupará muito, o que é verdade, mas em compensação também não ganhará nada. E sem apostar, ou melhor, sem se arriscar, não se atenta sobre os erros. É errando e acertando que se aprende sobre as carreiras hípicas, bem como sobre cavalos de corrida, porque eles nos oferecem a experiência. Assim é o mundo da percepção - ao menos no sentido de Merleau-Ponty (2004) - que é um mundo revelado por meio dos sentidos e da experiência pessoal. As experiências que temos com o mundo, seus objetos e os seus "outros", nunca são com coisas neutras

\footnotetext{
que contemplaríamos diante de nós; a cada uma delas simboliza e evoca para nós uma certa conduta, provoca de nossa parte reações favoráveis ou desfavoráveis, e é por isso que os gostos de um homem, seu caráter, a atitude que assumiu em relação ao mundo e ao ser exterior são lidos nos objetos [e nos "outros"] que ele escolheu para ter à sua volta, nas cores que prefere, nos lugares onde aprecia passear (Merleau-Ponty, 2004: 23).
}

A hipologia não é um conhecimento em que todos os turfistas pensam e agem de maneira igual, não existe uma "corrente" de pensamento, ou mesmo, uma Escola Hipológica da Gávea. No entanto, parece que muitos turfistas chegam a conclusões similares a respeito de quais são os melhores cavalos de cada páreo. Isto é notável através dos favoritismos dos páreos. Os turfistas conversam entre si sobre as corridas. É um momento de trocas de informação e de palpites, mas é sozinho que se estuda.

Aprender a decifrar os enigmas (ou as caixas-pretas) é uma tarefa individual, e é preciso ter o gosto por isso. Alguns dos aficionados me revelaram que já levaram os filhos para o hipódromo, mas que eles não "pegaram gosto pela coisa". Nas corridas de cavalo é preciso criar uma identificação, ou fascínio, com e pelos equinos e ter prazer pelo estudo hipológico. Tais sentimentos em relação aos cavalos podem ser ilustrados pela frase de Marco Aurélio Ribeiro, que dizia que o "turfe é paixão, o resto é esporte".

Noutra situação, quando o Professor - apelido de um senhor que é professor de matemática do Estado - após alguns páreos acertando, acabara de ganhar com uma acumulada de placê que surpreendeu a todos os rapazes, principalmente por acertar um cavalo que não era o favorito do público, ele jogou o seu retrospecto de lado e disse, com satisfação: “Cansei de estudar! Professor não precisa mais estudar”. Os rapazes 
olharam para ele achando graça, mas ficaram em silêncio. Apenas Eduardo se manifestou:

- Que isso?! Aqui o estudo é diferente. Aqui se estuda com prazer.

- Mas eu estou cansado, já estou acertando demais. Vou ficar agora só assistindo o canter.

Evidente que dois páreos depois o Professor retomou seu retrospecto e, consecutivamente, as suas análises hipológicas.

De qualquer modo, a figura do catedrático não é a daquele que mais acerta, mas sim a daquele que mais entende, abrangendo, é claro, as possíveis ambivalências, pois acertar e errar são operações de igual valor, mostrando-se como frutos do acaso hípico, da imprevisibilidade comandada pelos cavalos. Afinal, se perguntar - como perguntei aos aficionados como são os procedimentos realizados por eles para selecionar um cavalo, entre tantos outros para apostar, a resposta será: “É fácil! Cada páreo tem, mais ou menos, oito cavalos. Cada cavalo tem quatro patas. Então, todos têm as mesmas chances de ganhar!".

Ao descrever as rinhas de galos balinesas, Geertz fala das emoções e os sentimentos que ela ressalta (como um vocabulário de sentimentos) para fins cognitivos. É por meio das emoções evocadas através da rinha "que a sociedade [balinesa] é construída e que os indivíduos são reunidos" (Geertz, 1989: 210). Assim, para o balinês as apostas nas rinhas são como uma espécie de educação emocional. Destarte,

os balineses vão às brigas de galos para descobrir como se sente um homem, habilmente composto, afastado, quase obsessivamente auto-absorvido, uma espécie de autocosmo moral, quando, depois de atacado, atormentado, desafiado, insultado e, em virtude disso, levando a paroxismos de fúria, atinge o triunfo total ou o nível mais baixo (Idem, Ibidem: 211).

Deslocando essa pedagogia emocional para nosso contexto carioca e turfístico encontramos algo de similar. Um controle sobre si mesmo. Alguns rapazes haviam me relatado algo parecido com o que Barroca me disse certa vez: “já perdi muito nisso aqui. Perdi já todo o meu salário, mas eu fui burro em querer recuperar o que tinha perdido. Demorei muito tempo para aprender a jogar". E, depois, ainda explicou: "o objetivo disso aqui é você chegar em casa e não discutir com o porteiro, não chutar o cachorro e não brigar com a patroa; tem que sair sossegado". É como ditou Bull no décimo 
mandamento: "ganhando ou perdendo, tente ser objetivo e adulto". E "só aposte quando puder se dar ao luxo de perder", escreveu Bukowski (1976) em Dicas de cocheira sem a menor sujeira:

\begin{abstract}
quero dizer, sem depois ter que dormir num banco de praça ou se privar de 3 ou 4 refeições. O essencial é primeiro pagar o aluguel. Evitar problemas. Terá mais sorte. E lembre-se do que dizem os profissionais: "se tiver que perder, perca com classe". Noutras palavras, desafie os outros a derrotarem você. Se de um jeito ou doutro tiver que perder, então mande tudo para o inferno, pegue alguém para dançar nos portões de saída, a vitória é tua enquanto ninguém te derrotar, até que passem por cima do teu cadáver (Bukowski, 1976: 113).
\end{abstract}

Os cavalos, de alguma forma, têm muito a ensinar aos homens. Como tentei demonstrar aqui, mais do que o controle econômico e de si, eles oferecem o desafio da compreensão dos sinais equestres, ou mesmo, da possibilidade de comunicação, mas também a se autocontrolarem. Isto torna os equinos os vértices profundos e absorventes do turfe. Como indiquei acima, há o clima de suspeita sobre os homens que impregna todo o hipódromo, onde todos são malandros. Isto é natural, uma vez que é um jogo em que o somatório das apostas - o prêmio - é rateado pelo número de apostadores vencedores. Mas são os cavalos os responsáveis por minimizarem as suspeitas, porque eles são o diferencial desta atividade, ou como dizem, é "o fator animal” da atividade.

Os cavalos, diferente dos seres humanos, são incorruptíveis. E isso é uma ideia comum pelas tribunas. É impossível - creio eu e todos na arquibancada - subornar um cavalo, seja com alfafa extra ou com cenouras frescas, para correr mais ou simplesmente "entregar o jogo". Além do mais, o cavalo não pode informar seu estado psicológico e emocional do dia: se está confiante, se está triste, com medo, uma dor de barriga, se está com vontade de correr, entre tantas outras coisas. A comunicação neste nível é impossível. O exame veterinário apenas diz sobre as condições físicas do cavalo: se apresenta claudicância, se está com hemorragia, entre outras possibilidades. Assim, o problema está nos bípedes, e não nos quadrúpedes.

As figuras em que recaem as maiores suspeitas são as que lidam com os animais - treinadores e os jóqueis - que, por serem humanos, por isso mesmo são passíveis de se por à venda pela ganância. $\mathrm{O}$ treinador pode dopar o animal seja para correr mais ou menos. O jóquei pode conduzir o animal de forma que o leve a derrota. Existe o exame antidoping e uma comissão de corrida que apura e pune tais casos. Mas apesar da existência dessas deturpações, crê-se que, ainda assim, quando o animal quer vencer, 
não tem medicamento ou jóquei que o atrapalhe. Os cavalos são, nessa circunstância, superiores aos homens. Superiores porque são o ponto da dúvida.

O que os cavalos dizem no canter é outra coisa. O que eles dizem, apenas os turfistas, por meio da subjetividade, interpretam. Sá (2013), ao pesquisar a relação entre primatólogos e primatas na floresta, diz que os macacos notam que são observados e que os pesquisadores se pretendem como observadores despercebidos. E expõe que as relações entre ambos é intersubjetiva, entre sujeito (pesquisador) e sujeito-objeto (macacos). Estas relações intersubjetivas são "aquelas que se notabilizam por alguma troca de experiência entre sujeitos, resultando em algum ganho efetivo ou alguma transformação em ambos os termos nelas envolvidos, e inexistente no tempo que as precederam" (Idem, Ibdem: 128). Um fluxo mútuo de mudanças e de transformações nos termos que compõem a relação entre homem e animal. Nas corridas, os cavalos não são objetos estáticos, mas são sujeitos com características individuais particulares. Porém, as trocas entre homem e animal são diferentes. É o homem quem observa o cavalo e não ambos. E o cavalo pode ignorar que esteja sendo observado ou saber que está sendo observado, mas, isso não significa que ele mudará o seu desempenho, seja para melhor ou pior, para agradar ou desagradar o público que o assiste, no sentido mesmo goffmaniano de representação (Goffman, 2005). As intenções e a leitura das ações e dos gestos dos cavalos são todas atribuições humanas. É o homem por meio de suas especulações hermenêuticas e semiótica quem se transforma, o cavalo não (ao menos falando no sentido do espetáculo das corridas equestres).

Isto me faz lembrar uma passagem em Dom Casmurro, onde Bentinho, ao buscar os sentidos e significados da passagem "ele fere e cura", que diz ter buscado

\footnotetext{
em livros velhos, livros mortos, livros enterrados, a abri-los, a compará-los, catando o texto e o sentido, para achar a origem comum do oráculo pagão e do pensamento israelita. Catei os próprios vermes dos livros, para que me dissessem o que havia nos textos roídos por eles.

- Meu senhor, respondeu-me um longo verme gordo, nós não sabemos absolutamente nada dos textos que roemos, nem escolhemos o que roemos, nem amamos ou detestamos o que roemos; nós roemos (Machado de Assis, 2000: 35).
}

Talvez, se o antropólogo também pudesse "catar", ao final das corridas, os cavalos - tal como faz com os seus observados, os humanos -, quem sabe, não respondessem algo de semelhante à resposta do longo verme gordo. Ou, quiçá, responderiam outra coisa provando que estou equivocado, mostrando que minhas 
próprias observações então calcadas em inexatidões. De qualquer modo, o que os cavalos falam eles não nos explicam, permanecendo assim um enigma. Acerta aquele que ouviu o que cavalo "disse" ou aquele que acha que o "ouviu".

\section{Referências}

ABUJAMRA, Samir. Turfe: história e memória. São Paulo: Arte \& História, 2011.

BARCELLOS, Sergio. Cavalos de corrida: uma alegria eterna. Rio de Janeiro: Topbooks, 2002.

BUKOWSKI, Charles. Crônicas de um amor louco. Porto Alegre: L\&PM, 1976.

CARVALHO, Ney O. R. (Ed.). Jockey Club Brasileiro 130 anos: Rio de Janeiro, um século de turfe. Rio de Janeiro: Jockey Club Brasileiro, 1998.

CASSIDY, Rebecca. The social practice of racehorse breeding. Society and Animals, v. 10, n. 2 , 2002.

CASSIDY, Rebecca. Turf wars: arab dimensions to British racehorse breeding. Anthropology today, 13 (3), 2003.

EDMUNDO, Luís. O Rio de Janeiro do meu tempo. Brasília: Senado Federal; Conselho Editorial, 2003.

GEERTZ, Clifford. A interpretação das culturas. Rio de Janeiro: LCT, 1989.

GOFFMAN, Erving. As representações do eu na vida cotidiana. Petrópolis: Vozes, 2005.

HUIZINGA, Johan. Homo ludens: o jogo como elemento da cultura. São Paulo: Perspectiva, 2010.

LATOUR, Bruno. Ciência em ação: como seguir cientistas e engenheiros sociedade afora. São Paulo: UNESP, 2000.

MACHADO DE ASSIS, Joaquim Maria. Dom Casmurro. São Paulo: Ática, 2000.

MERLEAU-PONTY, Maurice. Conversas, 1948. São Paulo: Martins Fontes, 2004.

SÁ, Guilherme. No mesmo galho: antropologia de coletivos humanos e animais. Rio de Janeiro: 7 letras, 2013.

THOMAS, Keith. O homem e o mundo natural: mudanças de atitude em relação às plantas $e$ aos animais (1500-1800). São Paulo: Companhia das Letras, 2010.

VELASQUEZ, Rafael. Ciência inexata: corrida de cavalo \& antropologia. Dissertação de Mestrado - Programa de Pós-Graduação em Antropologia Social, UFF, Niterói, 2015.

Recebido em: 24/12/2015.

Aprovado em: 05/12/2016. 